Fredy Parra C.

Profesor de la Facultad de Teología

Pontificia Universidad Católica de Chile

\title{
Desafío del tiempo, memoria y esperanza
}

Las notas que se presentan desarrollan los siguientes puntos:

1. La existencia temporalizada y la estructura fundamental del tiempo

2. La historicidad

3. Tensión libertad-necesidad, ideología-utopía

4. Antropología de la esperanza

5. Historia y progreso

6. Historia, tiempo y teología

\section{LA EXISTENCIA TEMPORALIZADA Y LA ESTRUCTURA FUNDAMEN- TAL DEL TIEMPO}

El ser humano es y deviene a la vez. Mejor dicho, es en devenir (1). Se trata, en efecto, de una existencia temporalizada inserta inexorablemente en el tiempo, cuya vida se despliega dinámicamente en el mundo experimentando las diversas dimensiones del tiempo. Sin duda es un problema complejo asumir adecuadamente las dimensiones internas del tiempo. Para el lenguaje común el tiempo parece ser la secuencia de pasado, presente y futuro. Es discutible hasta qué punto es real esta comprensión que afirma en sí mismos a estos modos del tiempo. Tanto Aristóteles (2) como San Agustín (3) advirtieron sobre las contradicciones de tal lenguaje. Difícil es afirmar la consistencia del tiempo si observamos que por una parte, ha sido, pero ya no es: este es el pasado; por otra, va a ser, sin serlo todavía: este es el futuro. El presente queda definido como un límite entre pasado y futuro. "El pasado y el futuro no pueden ser transcritos como un mero 'ya no'; la experiencia del recuerdo y la de la espera lo impiden" (4). Lo mínimo que se puede afirmar al respecto es que "la presencia está en sí misma constituida en relación con el doble no ser del pasado y del futuro" (5) y que la conciencia del tiempo y de la historia "es

(1) V. MELCHIORRE, Historia, en Diccionario Teológico Interdisciplinar III, Sígueme, Salamanca, 1982, p. 30.

(2) ARISTÓTELES, Física, Libro IV, cap. 10.

(3) SAN AGUSTÍN, Confesiones, XI.

(4) MELCHIORRE, o. c., p. 32.

(5) Ibíd. 
auténtica en la medida en que no está ligada a la pura identidad del presente, y también en la medida en que no se engaña en la posibilidad de reconstruir un pasado abstracto. En resumen, es -como ha señalado Marrou (6)- 'dialectique du meme et de l'autre"' (7). Ahora bien, esta autenticidad no ha sido, precisamente, la nota característica de las interpretaciones occidentales más recientes de la historia. $\mathrm{N}$. Berdiaev, en el transcurso de la primera mitad del siglo pasado, supo advertir sobre las aporías de un tiempo sin fin (8) y sobre la incapacidad de la teoría del progreso para superar la disociación entre el pasado, el presente y el futuro (9).

Con todo, un desafío permanente es cómo asumir el tiempo en toda su complejidad e integridad. Al respecto, la propuesta de X. Zubiri parece sugerente. Como ha señalado Zubiri, el sujeto no solo es sujeto numerante, que cuenta el tiempo, y que, también retiene, sino que a la vez es un sujeto que proyecta -como lo destacó Heidegger- y que además está emplazado, es decir, hay proyecto si hay vida y si se persiste en ella (10). Para entender inicialmente este planteo parece oportuno reseñar a continuación algunos trazos importantes de la reflexión zubiriana sobre el tiempo.

Para Zubiri el ser humano, ser corporal y mundano, está sometido al tiempo. Es un ser en el tiempo. La vida se despliega en una tensión dinámica. En esa tensión, la vida se despliega en una sola estructura en tres fases cualitativamente distintas: el hombre nace, discurre por la vida, muere a la vida. El tiempo, en términos de Zubiri, se articula en tres dimensiones o estructuras fundamentales. La primera estructura del tiempo es, por tanto, la duración que da al tiempo su carácter de tardanza: la persona humana tarda un cierto tiempo en hacer sus movimientos, en realizar sus operaciones vitales, haciendo posible el cuánto y el cuándo. El tiempo de la duración como tardanza se organiza como una línea duracional en la que cada uno de los momentos es un ahora, un antes y un después.

Pero la persona humana no solo "dura", sino que fundamentalmente "proyecta". Ahora bien, el proyecto nos abre a otra dimensión, casi contraria. En la duración, el antes, el ahora y el después, no pueden invertirse si la duración es real y efectiva. En cambio, cuando el hombre proyecta dirige su atención a lo que todavía no es, al que trata de anticipar de algún modo, y también tiene conciencia de lo que fue, del pasado que recuerda. La proyección da al tiempo su carácter de futurición. En este caso, la realidad proyectiva se organiza también en tres momentos: pasado, presente y futuro. La unidad pasado-presente-futuro no es la unidad de un despliegue, como acontece en la duración, sino la unidad de una implicación en cada instante. Todo cuanto desde el punto de vista de la realización de unas potencias es un 'hecho', desde el punto de vista de la proyección es el logro o malogro de

(6) H. I. MARROU, De la connaissance historique, Paris, 1959, p. 88.

(7) MELCHIORRE, o. c., p. 33.

(8) “Así pues, para una verdadera conciencia histórica, nada hay más importante que establecer la relación justa con el pasado y el futuro. El culto exclusivo al futuro y el rechazo del pasado, característicos de las diferentes teorías basadas en la idea del progreso someten la vida a un principio aniquilador, mortífero, que destruye los vínculos y rompe la integridad de la realidad" (N. BERDIAEV, El sentido de la historia, Ed. Encuentro, Madrid, 1979, p. 74).

(9) Cf. N. BERDIAEV, El sentido de la historia, pp. 165-182; Id., Essai de métaphysique eschatologique, Aubier, Paris, 1946, pp. 257-263.

(10) X. ZUBIRI, Sobre el Hombre, Ed. Alianza, Madrid, 1986, pp. 622-625. 
posibilidades; es un 'acontecer'. En la línea proyectiva, el hombre elige unas posibilidades que va a poner en ejecución, de tal modo que con esa decisión ejecutiva deja de lado unas posibilidades y toma otras con las que se encuentra comprometido para la próxima decisión. Cada instante es cuestión de decisiones, y por ello el hombre solo puede contar con un futuro relativamente próximo. En definitiva, la dialéctica del acontecer no es la duración tensa de los hechos, donde cada instante deja de ser para dar paso a un instante sucesivo, sino que es la construcción decidida de las posibilidades. Mientras el tiempo de la duración se vive como tardanza, el tiempo de la proyección se vive como futurición. Estas dos dimensiones estructurales del tiempo no son independientes: necesito tiempo para proyectar y la duración subyace a mi proyecto.

La proyección apunta a otra dimensión que no es la duración. El intento de poner en ejecución un proyecto le pone a la persona de manifiesto que monta sus proyectos sobre lo que podemos denominar un plazo. Tanto la duración como la proyección están bordeadas por un futuro indeterminado. Se trata de la dimensión de "destinación", que da al tiempo su carácter de emplazamiento. La vida es constitutivamente emplazamiento. El emplazamiento como futuro indeterminado e indeterminable pertenece radicalmente al tiempo de la vida: el tiempo de mi vida está, por así decirlo, contado, tiene un emplazamiento. En este caso, la vida transcurre entre un comienzo, un camino y un fin. Somos viadores, estamos en la vía, en el camino de un emplazamiento (11). La muerte como vivencia e ingrediente de la vida, es la experiencia de la temporalidad como emplazamiento final. La muerte, en suma, es tránsito hacia el futuro absoluto prometido por Dios.

Digamos algo sobre las diversas dimensiones del tiempo como proyección. El futuro no es sin más lo que todavía no es. En su realidad positiva, es el porvenir que he decidido llegue a ser. Solo cuando cuento con las posibilidades reales y anticipables para proyectarlo, puedo hablar de futuro. Por su parte, el pasado como realidad duracional ya no existe. Pero el hombre es de por sí retinente. Aquí ocupa un lugar central la memoria. Al respecto, San Agustín nos enseña: "Todo esto lo hago yo interiormente en el aula inmensa de mi memoria. Allí se me ofrecen al punto el cielo y la tierra y el mar con todas las cosas que he percibido sensiblemente en ellos, a excepción de las que tengo ya olvidadas. Allí me encuentro conmigo mismo y me acuerdo de mí y de lo que hice, y en qué tiempo y en qué lugar y de qué modo y cómo estaba afectado cuando lo hacía. Allí están todas las cosas que yo recuerdo haber experimentado o creído. De este mismo tesoro salen las semejanzas tan diversas unas de otras, bien experimentadas, bien creídas en virtud de las experimentadas, las cuales, cotejándolas con las pasadas, infiero de ellas acciones futuras, acontecimientos y esperanzas, todo lo cual lo pienso como presente" (12).

Este significativo texto de San Agustín nos sugiere las siguientes reflexiones. Por una parte, estamos frente a una superación del tiempo físico y cronológico. En el hombre, el tiempo adquiere consistencia. Mientras el tiempo físico se plantea

(11) Para seguir el desarrollo del análisis de ZUBIRI, sobre el "Decurso vital" consultar su obra antropológica "Sobre el Hombre" entre las páginas 545 y 671.

(12) SAN AGUSTÍN, Las Confesiones, Obras de San Agustín, T.II, BAC, Madrid, 1951, Libro X, \& 14, p. 479 
como un espacio de unidades cronológicas finitas y exteriores entre sí -el futuro como exterior al presente, el presente como exterior al pasado- en la experiencia humana del tiempo, pasado, presente y futuro se imbrican mutuamente. Pensando sapiencialmente el tiempo, se descubre la acumulación de tiempo -pasado, presente y futuro- en el instante. Explica que "los tiempos son tres: presente de lo pasado, presente de lo presente, presente de lo futuro. Porque estas tres cosas existen en el alma, y fuera de ella no las veo" (13). En la propia conciencia están de algún modo presentes las tres dimensiones del tiempo que a su vez corresponden a las facultades humanas de la memoria, de la visión y de la espera.

En efecto, el pasado está contenido en el presente. El futuro está presentido en el presente y le pertenece como proyecto. La memoria hace posible conservar el pasado. Si ese pasado no fuese real ahora, este 'ahora' estaría como vacío. Por otra parte, la memoria dice relación con identidad: "Allí me encuentro conmigo mismo y me acuerdo de mí y de lo que hice...". La memoria aporta conciencia de la propia mismidad, aporta identidad: yo soy el mismo de ayer... Reivindicamos el pasado como propio, sea en términos individuales o colectivos. Finalmente, la memoria dice relación con la acción futura: “...salen las semejanzas... cotejándolas con las pasadas, infiero de ellas acciones futuras...". Comparando experiencias se infieren acciones futuras. La memoria articula y reorienta la acción.

Empero, el ser humano es retinente no solo porque es capaz de recuerdo y memoria, sino porque también en el campo de la libertad se "hace presente" el pasado: la libertad aparece comprometida por la realización de decisiones anteriores que deja un juego de posibilidades anteriores para enfrentar la nueva situación. En otras palabras, el pasado no pervive en forma de realidad; pervive en forma de posibilidades para afrontar la nueva situación. Por ello, J. Marías puede afirmar: "lo que pasa, nos pasa, es decir, nos toca, nos atañe. Por eso, lo que pasa se queda" (14). Asimismo, tampoco el presente es sin más el ahora de la duración temporal inscrito entre un antes y un después como punto de inserción de un continuo. Es la situación en que me dejó el pasado para hacer frente desde ahora al futuro y a la futurición.

En suma, el tiempo de la vida humana es a la vez: duración, proyección y emplazamiento. Es decir, el ser humano necesita durar para proyectar. La duración forma parte interna de la modulación del proyecto. Lo mismo se puede decir del plazo: porque si supiésemos cuánto vamos a durar, nuestros proyectos serían distintos. La unidad del tiempo humano estriba en la unidad de la triple dimensión del ser-hombremujer, quien es a una agente, autor y actor de su existencia y acciones. El sujeto es radicalmente tempóreo, inquieto: la inquietud da la unidad al tiempo humano (15).

El hombre es ahora por algo (por lo que ha sido) y para algo (para lo que será). Por ello, "el presente es la forma más real de ser y, al mismo tiempo, la más enajenada de ser propio. Si es cierto que el hombre no puede vivir sino en el presente, no lo es menos que el presente no puede ser vivido sino como fruto del pretérito y anticipación del futuro" (16).

(13) Ibíd., XI 20, 26.

(14) J. MARÍAS, Antropología metafísica, Madrid, 1970, p. 247.

(15) Cf. ZUBIRI, o.c., p. 618s.

(16) J. L. RUIZ DE LA PEÑA, La otra dimensión. Escatología cristiana, Sal Terrae, Santander, 1986, p. 20. 
Ahora bien, si el ser humano es en devenir habrá que decir entonces que pasado y presente están en función del futuro. Y dado que el hombre, autor, sujeto libre, estructura el tiempo como tarea y proyecto, habrá que reconocer una primacía al futuro.

El poder del futuro se debe en última instancia a que el hombre se capta como una entidad inconclusa, abierta, inacabada, en camino hacia una plenitud oscuramente presentida en su experiencia actual y contingente. Al aludir a esta experiencia de finitud se sugiere otro futuro, un futuro de plenitud deseado. El devenir humano del ser al ser más supone un futuro diverso y mejor, un futuro nuevo. Es decir, supone la posibilidad de una novedad real, más allá de los procesos causales (sociales o técnicos). Si el futuro tiene sentido para el hombre es, precisamente, por lo que puede ofrecer de nuevo (17).

Siguiendo a N. Berdiaev, lo anterior implica que en la potencia hay más que en el acto, en el movimiento hay más que en la inmovilidad. Ahora bien, el movimiento y el poder de creación existen en el tiempo (18). La posibilidad de llegar a un acto creador, de manifestar un cambio y una novedad es solidaria de la imperfección. De la finitud surge, precisamente, la aspiración a la infinitud. La novedad nace de un sufrimiento profundamente vivido. Esto quiere decir que en lo que se ha vivido había un elemento creador, una actitud creadora frente al sufrimiento. Y esta experiencia es inexplicable por la serie objetiva de las relaciones causales. Por ello, la novedad creadora no es evolucionismo.

Como ya se ha dicho, sin tiempo no hay lugar para el cambio, la novedad surge y aparece en el tiempo, y el tiempo existe porque el movimiento y la novedad existen. El hecho de que el mundo exista en el tiempo y no solamente en el espacio significa que el mundo no está acabado, y que él continúa creándose. El sujeto está inevitablemente sumergido en la objetividad del mundo, en el tejido de la realidad en cuanto objetividad, pero también es una realidad más profunda: la de la potencialidad, campo propio del cambio, del acto creador, de la Novedad. Y esta novedad auténtica se lleva a cabo en el tiempo no objetivo, es decir -observa Berdiaev-, "según la vertical y no según la horizontal" (19). En otro lugar, el pensador ruso añade que la novedad auténtica "llega siempre como de otro mundo, de otro plan, llega de la libertad", de la libertad vivida en la historia, "el acto creador se presenta de una forma paradójica como viniendo del futuro" (20). Al respecto, Ruiz de la Peña, afirma que "la diferencia específica del futuro auténtico (abierto hacia la novedad) se debe a la libertad del ser personal. Historia es más que tiempo; es el tiempo vivido por la libertad. Lo histórico jamás podrá ser previsto en la planificación, porque propio de la libertad es su impronosticabilidad. El futuro de ese ser histórico que es el hombre está puesto bajo la reserva de lo imprevisible porque la libertad es esencialmente creadora" (21). "Nos hallamos así ante un concepto de futuro que se despliega en dos niveles. El futuro para ser auténticamente humano,

(17) J. MOLTMANN, Esperanza y planificación del futuro, Salamanca, 1971, p. 424.

(18) Cf. N. BERDIAEV, Essai de métaphysique eschatologique..., p. 182ss.

(19) Ibíd., p. 188.

(20) Ibíd., p. 194.

(21) RUIZ DE LA PEÑA, La otra dimensión..., p. 22. 
debe tener un elemento de continuidad (de lo contrario no podría ser mi futuro) ... y debe entrañar, a la vez, un elemento de novedad" (22). Por una parte, el futuro procede del pasado y presente, está, de algún modo, precontenido en ellos, y, por otra, futuro es lo que la libertad humana puede crear y realizar.

Ahora bien, no corresponde oponer antinómicamente ambos niveles de futuro. Han de ser vistos en relación: "el futuro proyectable es el horizonte categorial (la mediación creada) del futuro imprevisible". Hay una dialéctica de continuidad-ruptura; identidad-diversidad permanente de la que estos dos niveles de futuro son una elocuente expresión. El ser humano, en suma, "se encuentra abocado a un futuro que, visto en su integridad, podría ser designado como 'futuro absoluto' (23). Su temporalidad constitutiva lo inserta en un acontecer que no fluye hacia el vacío, ni tan solo hacia las posibilidades latentes en la estructura intramundana de la realidad, sino hacia una consumación que le ofrezca un plus de ser... La existencia humana, perennemente tendida a su autotrascendencia, tiene sentido únicamente en el encuentro con un futuro absolutamente último, más allá del cual no hay nada digno de prolongar el camino" (24).

\section{LA HISTORICIDAD}

El hombre como pueblo histórico, además de estar en relación con los otros de su presente, está también en relación con todos sus antepasados y, al mismo tiempo, está permanentemente fundando la relación con los que vendrán. De este tiempo y espacio históricos se tejen las relaciones interhumanas de todas las generaciones. El pasado está presente aquí y ahora. Todos los cultivos históricos (lenguaje, costumbres, ritos, instituciones, estructuras sociales, etc.) están en todos y cada uno de nosotros. Y todo esto irreversiblemente empujando hacia el futuro. El futuro es posibilidad permanente. La historia es cambio, evolución y, gracias a la mediación trascendente del hombre, es superación, trascendencia.

El hombre moderno adquiere la conciencia de estar inserto en una historia que está hecha por el propio hombre. La modernidad comprende la realidad históricamente. El marco espiritual antiguo y medieval que había condicionado toda interpretación de la historia entró en crisis definitiva a comienzos del siglo XIX. En diversos niveles se empieza a descubrir la dinamicidad de lo que aparentemente era inmutable. Como bien explica J. Ratzinger, "todos los campos del espíritu humano cambiaban de la pregunta por el ser a la pregunta por la historia: la filosofía con Hegel, la economía nacional con Marx, la teología con F. Chr. Baur, la ciencia natural a su modo (...) con Darwin. En lugar de la resolutio in theologiam llega la resolutio in historiam. La historia se hace una forma que lo domina todo. La historicidad es la categoría fundamental bajo la que el hombre aprende ahora a entenderse nuevamente a sí mismo. El mismo no existe sino como un ser que se hace y todas sus imágenes están bajo el signo de la historia y solo se pueden comprender dentro de ella" (25).

(22) Ibíd., p. 22

(23) K. RAHNER, Escritos de Teología VI, Madrid, 1969, pp. 78-81.

(24) RUIZ DE LA PEÑA, La otra dimensión..., p. 23.

(25) J. RATZINGER, Teología e historia, Sígueme, Salamanca, 1972, p. 78. 
La nueva comprensión conduce a una modificación en la imagen del mundo. G. Greshake explica que "hasta la época moderna, la realidad se concebía principalmente según el esquema de los dos mundos: el más acá y el más allá. Se concebía el más acá como un espacio destinado y preordenado por Dios para el hombre y que, en sus estructuras esenciales, era inmutable y estático. Dentro de este espacio, la historia humana se desarrollaba como un incesante devenir y pasar que, en sí mismo, no tiene ningún sentido ni meta hacia la que tender. El sentido de la historia se reduce a ser para el hombre el tiempo de la prueba, es decir, a ofrecerle las condiciones para poder prepararse para el mundo del más allá por medio de su obrar ético-religioso" (26). La modernidad, por el contrario, "concibe este mismo mundo como historia, es decir, como un potencial casi ilimitado y un inmenso campo material que le ha sido confiado al hombre para que este lo conforme a sus objetivos e ideales, lo someta a sus deseos de felicidad y, de este modo, se construya para sí un futuro último de salvación" (27). El futuro es lo que el ser humano, mediante su acción y trabajo, puede y debe realizar. En este contexto la historia se refiere a toda la realidad considerada en su dinamicidad. Es decir, no se refiere solo al conocimiento de lo que sucedió en el pasado (historia fáctica) sino al acontecer mismo, al presente en su apertura a la novedad que trae consigo el futuro. Este carácter aconteciente se designa acertadamente con la expresión 'historicidad'.

La 'historicidad' en este sentido indica el modo propio del existir humano y que hace posible el carácter esencialmente histórico del ser humano. A. Darlap- J. Splett, logran elaborar un concepto sugerente de historicidad y la definen como "aquella constitución de la existencia humana (que reúne el mundo y el tiempo) por la que el hombre se encuentra entre un pasado ya dado, todavía operante y sustraído a su acción, de una parte, y un futuro por crear, por venir, que está llegando en todo momento, de otra. Y así él, en medio de la estructura interpersonal y de la tensión entre libertad y predeterminación se produce a sí mismo con su propia naturaleza. Esta estructura esencial lleva consigo el hecho de que el hombre adquiera conciencia de su historia e historicidad también históricamente, y la asuma de ese mismo modo en medio de un diálogo crítico con ella" (28).

Todo ser humano se sitúa en la tensión entre un pasado ya realizado (tradicióncultura de generaciones anteriores) y la novedad que conlleva un futuro susceptible de ser realizado personal y socialmente. El hombre no solo se descubre como viviendo en el tiempo, sino como una existencia con una tarea que no es otra que su propia realización. Como creador de su vida, el ser humano es un sujeto libre, capaz de intervenir en el devenir histórico de acuerdo a las metas humanas que se propone. Por la libertad, el sujeto es capaz de distanciarse del pasado y del presente y abrirse a un futuro diverso. Por la misma libertad es capaz de aceptar libre y críticamente el pasado y los condicionamientos propios de la tradición histórica que influyen constantemente en el presente.

La misma conciencia de la historicidad ayuda a percibir que acontecimientos del pasado pueden ser significativos para la actualidad y en la misma medida funda-

(26) G. GRESHAKE, Más fuertes que la muerte, Sal Terrae, Santander, 1981, p. 37.

(27) Ibíd., p. 41.

(28) A. DARLAP-J. SPLETT, en Sacramentum Mundi, III, Barcelona, Herder, 1973, col. 429. 
mentar tanto la existencia presente como su apertura al futuro. En suma, el ser-enel-tiempo y en-el-mundo-con-los-otros define el modo de ser del sujeto humano libre que, por lo mismo, es capaz de hacerse y renovarse intersubjetivamente, determinar las determinaciones y ejercer su creatividad. La experiencia de la realidad como pasado, presente y futuro, esto es, la experiencia de la historia es, a su vez, la experiencia de la libertad. En palabras de K. Rahner, y como conclusión de este punto, la historicidad se refiere a "aquella peculiar determinación fundamental del hombre por la que él precisamente como sujeto libre está puesto en el tiempo y por la que está dispuesto para él el mundo respectivo, que el hombre debe crear y padecer con libertad" (29).

\section{TENSIÓN LIBERTAD-NECESIDAD, IDEOLOGÍA-UTOPÍA}

Aquí se plantea una de las grandes paradojas de la existencia histórica del ser humano tematizada también por el pensamiento moderno: la que surge de la polaridad libertad-necesidad. En efecto, devenir histórico y libertad se especifican mutuamente en una relación dialéctica. El futuro está de suyo abierto, por lo mismo, no se presenta nunca de modo determinante y cerrado. Es siempre a la vez una posibilidad de ser y posibilidad de no ser. Sin embargo no se trata de una posibilidad pura. En efecto, "lo posible se predica de lo que ya es; no es nunca posibilidad pura, sino posibilidad de algo o de alguien... Así pues, incluso como alternativa del no ser, lo posible es siempre tensión hacia algo, no a la pura nada, a no ser que la búsqueda del no ser quiera anular a lo que es portador de lo posible, intentando el suicidio o el fin de la misma historicidad" (30). Y por la innegable presencia de la contradicción en la historia, el progreso del hombre no va entonces lineal e irreversiblemente del reino de la necesidad al de la libertad, ya que la libertad de lo posible -como se ha dicho- no puede surgir más que dentro de la necesidad. En esta situación, la conciencia histórica, sin renunciar a su intencionalidad esencial, la de un sentido absoluto, se preocupa de valorar los lugares más significativos y más dominantes de la contradicción histórica. Para esta valoración debe orientarse a "subrayar las totalizaciones históricas, tanto negativas como positivas. De este modo se abre el discurso sobre la posición privilegiada que en el análisis histórico llegan a ocupar la ideología y la utopía" (31).

Tanto el ya clásico K. Mannheim, Ideology and utopia del año 1929 (32), como la obra de P. Ricoeur, Ideología y utopía (1986) (33), sitúan la ideología y la utopía dentro de un marco común de análisis. Mientras que para Mannheim ambos fenómenos se pueden considerar como actitudes de desvío respecto de la realidad, que a la vez divergen dentro de ese aspecto común de incongruencia con la actuali-

(29) K. RAHNER, Curso fundamental sobre la fe, Ed. Herder, Barcelona, 5 a ed., 1998, p. 61.

(30) V. MELCHIORRE, o. c., p. 41.

(31) MELCHIORRE, ibíd., p. 44.

(32) K. MANNHEIM, Ideologia e utopia, 4a ed., Guanabara, Rio de Janeiro, 1986 (trad. bras.)

(33) P. RICOEUR, Ideología y utopía, comp. por G. Taylor, Ed. Gedisa, Barcelona, 1989. (Título del original en inglés: Lectures on Ideology and Utopia, Columbia University Press, New York, 1986) 
dad social, para Ricoeur la conjunción de estas dos funciones opuestas o complementarias tipifica la imaginación social y cultural. La hipótesis de Ricoeur es que "la dialéctica entre ideología y utopía puede arrojar alguna luz sobre la no resuelta cuestión general de la imaginación como problema filosófico" (34). Para Melchiorre la ideología y la utopía constituyen "la propuesta o el plan de una organización global de la historicidad, un plan que comprende todo lo que es y en cuanto ha de ser y que traduce el sentido del presente en una construcción integrada del futuro" (35), constituyen, en suma, el proyecto de una síntesis futura que al mismo tiempo pone en cuestión el presente y lo conducen más allá de sí mismo. Empero, ideología y utopía se diferencian y llegan a contraponerse dado que mientras el futuro de la ideología es solo aparente, mera repetición del presente, el futuro de la utopía es al parecer proyectable, cualitativo (36). Toda conciencia que quiera comprender y eventualmente transformar la realidad tiene que asumir críticamente las mediaciones ideológicas y utópicas.

Revisitar el concepto de utopía (37) así como el de ideología en su evolución histórica desde Francis Bacon, pasando por C. Marx y K. Mannheim, hasta desarrollos más actuales (38) y la recepción que se puede observar en la teología moral (39) y en los documentos del magisterio social (40) de la Iglesia permite establecer un diálogo crítico y fundamentar la diferencia entre ideología-utopía y Doctrina social de la Iglesia (41). Diferencia no fácil de precisar dada la ambigüedad que caracteriza a ambos fenómenos (42). Las funciones de la ideología transitan entre la deformación, la legitimación del poder y la integración social, por su parte, la utopía puede constituir una evasión de la realidad y, a la vez, su "ningún lugar" permite la distancia necesaria para repensar la sociedad (43). Por ejemplo, ya Pablo VI, en 1971, advertía con claridad que, en medio de la crisis de las ideologías entonces constatada, la apelación a la utopía podía ciertamente constituir una evasión de la realidad, "pero, sin embargo, hay que reconocerlo, esta forma de crítica de la socie-

(34) RICOEUR, o. c., p. 45

(35) V. MELCHIORRE, o.c., p. 44.

(36) Ibíd.

(37) RICOEUR, o. c., pp. 287-328; F. E. MANUEL -F. P. MANUEL, El pensamiento utópico en el mundo occidental, Taurus, Madrid, 1984; J. SER VIER, Histoire de l' utopie, Gallimard, Paris, 1967.

(38) K. LENK, Ideologiekritik und Wissenssoziologie, 5, Auflage 1971, Luchterland, Neuwied und Berlin, pp. 17-59; id., edición española: Concepto de ideología, Amorrortu Editores, Buenos Aires, 1974, pp. 9-46; Ricoeur, o. c.

(39) M. VIDAL, Moral de actitudes, T. III, Moral social, PS Editorial, Madrid, 1979, pp. 538-560; VV. AA., Praxis cristiana I y III, Paulinas, Madrid, 1980-1986; P. HÜNERMANN, Iglesia, praxis, institución. Sobre el método y las tareas de la doctrina social cristiana, en P. HÜNERMANN, J. C. SCANNONE, dirs, América Latina y la doctrina social de la Iglesia I, Ed. Paulinas, Buenos Aires, 1992, pp. 87-140; M. D. CHENU, La 'doctrine sociale' de l' Eglise comme idéologie, Cerf, Paris, 1979.

(40) Documentos de la DSI desde Rerum Novarum DE LEÓN XIII hasta Centesimus Annus de JUAN PABLO II.

(41) Al respecto me permito remitir a F. PARRA-P. MIRANDA, Pensamiento social de la Iglesia y ciencias sociales: horizontes teológicos para un diálogo, Anales de la Facultad de Teología, Vol. LVII, C.2, PUC, Santiago, 2006, pp. 15-80.

(42) RICOEUR, o. c., p. 45 ss.

(43) RICOEUR, o. c., pp. 47-61. 
dad establecida provoca con frecuencia la imaginación prospectiva para percibir a la vez en el presente lo posiblemente ignorado que se encuentra inscrito en él para orientar hacia un futuro mejor" (OA, 37). Quien precisamente reflexionó sobre los fundamentos antropológicos de la utopía y destacó la categoría filosófica de "posibilidad" que aporta el pensar utópico fue el filósofo judío-alemán E. Bloch (44). La confrontación crítica entre los teólogos cristianos y el pensamiento de Bloch ha dado lugar a uno de los capítulos notables y fecundos del pensar teológico-escatológico del siglo XX y continúa, de alguna manera, hasta nuestros días (45). La crítica de la utopía a la teología y de esta a la utopía (46) constituye, hoy y aquí, un imperativo mayor sobre todo cuando livianamente se declara la "muerte" de todo pensamiento utópico e incluso del hombre histórico (47). Tampoco es posible ignorar el serio cuestionamiento a la utopía planteado por la sensibilidad postmoderna que subraya el incumplimiento de las promesas utópicas de la modernidad (48). La articulación entre esperanza cristiana y futuro histórico continúa siendo un desafío y conlleva cuestiones y tareas aún no resueltas (49). Más recientemente, tras la huella del pensamiento del filósofo X. Zubiri, en especial en su visión de la historia (50), el teólogo español A. González rescata de nuevo la categoría de "posibilidad" en relación con la praxis (51), vuelve a releer la decisiva contribución de J. Moltmann en su diálogo con E. Bloch, desde las actuales circunstancias históricas a comienzos de este incierto siglo XXI y ensaya una nueva crítica (52).

De todos modos, la historia-historicidad llevará siempre la impronta de la dialéctica entre libertad y necesidad, una mutua limitación de facticidad y trascendencia, de poder y debilidad del hombre. Pero estos binomios no son ámbitos yuxtapuestos en la experiencia vital del ser humano: "precisamente en su trascendencia experimenta una y otra vez su inmanencia. Pero también lo contrario: precisamente en su miseria se prueba su grandeza, puesto que el hombre la conoce y sufre por su causa. Pues no podría sufrir por ella si al menos no tuviera un presentimiento de su grandeza y, en consecuencia, no supiera que todo podría y tendría que ser distinto" (53). La conciencia se manifiesta fundamentalmente como apertura, pregunta y peti-

(44) E. BLOCH, Principio Esperanza, Aguilar, Madrid, 1980. (I-III).

(45) J. MOLTMANN - L. HURBON, Utopía y esperanza. Diálogo con Ernst Bloch, Ed. Sígueme, Salamanca, 1980; J. MOLTMANN, Teología de la esperanza, $3^{\mathrm{a}}$ ed., Ed. Sígueme, Salamanca, 1977; J. NOEMI, ¿Es la esperanza cristiana liberadora?, Ed. Paulinas, Santiago de Chile, 1990; id., Modernidad y esperanza, Teología y Vida, Vol. XXXVIII (1997), pp. 122-138.

(46) J. L. RUIZ DE LA PEÑA, La pascua de la creación. Escatología, BAC, Madrid, 2000 (1ª ed. de 1996).

(47) L. KOLAKOWSKI, Tras la muerte del hombre histórico, Letra Internacional, $\mathrm{N}^{\mathrm{o}} 23$, Madrid, 1991, pp. 72-75.

(48) G. VATTIMO, El fin de la modernidad, Ed. Gedisa, Barcelona, 1986; J. F. LYOTARD, La condición postmoderna, Madrid, 1984.

(49) F. PARRA, Esperanza cristiana y futuro histórico (pensamiento escatológico en la revista Teología y Vida en los últimos cuarenta años), Teología y Vida, Vol. XLI (2000), pp. 562-590.

(50) X. ZUBIRI, Naturaleza, Historia, Dios, Alianza, Madrid, 1987; id., Inteligencia y razón, Alianza, Madrid, 1983; id., Estructura dinámica de la realidad, Alianza, Madrid, 1995.

(51) A. GONZÁLEZ, Estructuras de la praxis, Ed Trotta, Madrid, 1997.

(52) A. GONZÁLEZ, "La razón de la esperanza", en VV. AA., De la esperanza a la solidaridad, SAT, Ed. San Benito, Buenos Aires, 2002,pp. 79-118.

(53) W. KASPER, Jesús, el Cristo, Salamanca, 1989, p. 66, recogiendo el pensamiento de B. Pascal (Pensées, \& 397, 409.416)). 
ción de una adecuación de sentido y en esa medida participa en lo absoluto como plenitud de sentido, sentido que se ha dado solo en ausencia y el que, sin embargo, atrae constante y poderosamente a la conciencia.

Finalmente, continúa la pregunta: ¿qué es lo que llena la libertad? "La historia ofrece el aspecto de una multitud inagotable de logros y pérdidas, de presencias y expectativas, de cosas y hombres, de deseos, pensamientos e ideas. (...) La pregunta por lo que llena no ha recibido respuesta. Cierto que cada cosa puede ser algo que llena más o menos, pero la respuesta según la cual cualquier cosa es contenido de la libertad no es ninguna respuesta, o a lo sumo es una respuesta extremadamente indiferente. La historia arroja la pregunta por lo que llena la libertad, porque ella es un producto de la libertad y su fin histórico universal es representado como realización de un reino de la libertad. Pero la historia no da respuesta a la pregunta" (54). En realidad, lo que llena la libertad es la otra libertad. Más concretamente: "el contenido por el que se llena la libertad y por el que la automediación alcanza la realidad plena, es la libertad del otro" (55). Con todo, la libertad es un concepto de comunicación. Bien señala Krings que "libertad no es primariamente la propiedad de un sujeto individual, la cual pueda existir y comprenderse por sí sola; más bien, el concepto individual solo puede entenderse por aquel concepto de comunicación. Empíricamente esto significa: un hombre solo no puede ser libre. La libertad solo es posible donde la libertad se abre a otra libertad" (56). Y la afirmación libre de la otra libertad y de las otras libertades solo podrá hacerse históricamente concreta en una sociedad que se asume como tal desde la afirmación originaria de la libertad.

\section{ANTROPOLOGÍA DE LA ESPERANZA}

El hombre es también un ser de deseo. Deseo es síntoma de privación, de ausencia. "Deseo pertenece a los seres que se sienten privados, que no encuentran placer en aquello que el espacio y el tiempo presente les ofrece" (57). Precisamente, la cultura desea crear el objeto deseado. Es posible discernir la intención del acto cultural, pero su realización efectiva siempre escapa. Y en cuanto el deseo no se realiza, está para cantarlo, decirlo, celebrarlo, escribirle poemas... etc. Y la realización de la intención de la cultura se transfiere entonces para la esfera de los símbolos.

El deseo, la fantasía creadora, la imaginación, nos revelan un ser humano simbólico y abierto a la trascendencia. Los símbolos de la ausencia son propios del ser humano como ser de la trascendencia. De un ser que busca incansablemente el sentido de su vida y que en esta búsqueda acaba encontrándose con el Absoluto. Este hombre no se queda en sí mismo, está abierto a los otros, abierto al mundo, donde quiere construir un mundo de amor con sentido. Supera lo inmedia-

(54) H. KRINGS, Libertad, Conceptos Fundamentales de Filosofía, II, Ed. Herder, Barcelona, 1979, p. 485 .

(55) Ibíd., p. 486.

(56) Ibíd., p. 487, el subr. es mío.

(57) Cf. R. ALVES, O que é Religiao, Brasiliense, São Paulo, 1981, pp. 19-20; O enigma da Religiao, Papirus, Campinas, 1984, p. 47. 
to, se abre al futuro. A pesar de que no se realiza ese mundo de amor, el hombre insiste y crea un universo simbólico: como testimonio de las ausencias, como protesta contra ese mundo que se resiste a sus deseos, como revelación de sus profundas contradicciones.

Con todo, el ser humano toma conciencia de las ausencias esenciales: el sentido de la existencia, y, en definitiva, Dios mismo. Consciente de su finitud, el hombre se capta en el presente como inconcluso, como inacabado, en camino hacia una plenitud ausente, presentida y expresada en su dimensión simbólica. Este mismo hombre es el que crea utopías. La esperanza llega a ser así un principio de la vida humana y del cosmos. Se basa en la diferencia crítica entre lo que es y lo que todavía no es, entre presente y futuro. El hombre como un ser no fijo es una gran tarea, una apertura constante hacia el futuro. Como se ha dicho se trata de un principio, no solo de una virtud, presente en el proceso del mundo y en el mismo sujeto humano. En este sentido la esperanza es el constitutivo más importante de la existencia humana. "Es la respuesta de todo el ser humano a la situación de cautividad existencial en que está sumido. Está inscrita en la estructura misma del ser humano: en su conciencia, en su libertad, en su historicidad, en su relación a y con los otros, en su relación a y con el mundo" (58).

En palabras de Laín Entralgo, "por el hecho de ser como es, el hombre tiene que esperar, no puede no esperar" (59). Entendemos la existencia humana entre el 'ya' de lo que somos y el "todavía no" que podemos ser, entre la inmanencia (conciencia de lo que ya somos) y la trascendencia (conciencia de lo que estamos llamados a ser).

Decimos que el hombre transciende, porque, al mismo tiempo que tiene conciencia de su limitación y finitud experimenta en esa misma conciencia los signos de la infinitud. En efecto, "la esperanza está presente y operante en la conciencia. El ser humano tiene conciencia de su finitud, de su negatividad, de su contingencia; pero tiene conciencia igualmente de su positividad, de ahí que viva con una inquietud radical y esté en tensión hacia su plenitud. La esperanza está presente y actúa dinámicamente también en la libertad humana. La esperanza es precisamente la que libera a la frágil libertad humana de caer en la frustración ante el fracaso real o posible. La mirada confiada al futuro libera a la quebradiza libertad humana de la frustración que genera la inseguridad de no lograr la propia realización" (60).

No hay duda que la esperanza entra en conflicto con la realidad. Es por ello que se le puede acusar de ilusión en nombre de la objetividad empírica. Pero sucede que la esperanza ve la realidad y también ve sus posibilidades. En ese sentido la verdadera Esperanza es realista, pues integra lo dado y lo que puede llegar a ser. Es así como este todavía-no-haber-llegado-a ser presenta la realidad como posibilidad. "La esperanza opera activamente en la relación del ser humano al mundo y con el mundo. Hay una convergencia entre las posibilidades ilimitadas ocultas en el mundo y la aspiración igualmente ilimitada del ser humano, entre la fluidez y el dinamismo

(58) J.-J. TAMAYO-ACOSTA, Para comprender la escatología cristiana, Ed. Verbo Divino, Estella, 1993 , p. 20.

(59) P. LAÍN ENTRALGO, Antropología de la esperanza, Guadarrama, Barcelona, 1978, p. 10.

(60) TAMAYO-ACOSTA, o. c., p. 20. 
de la realidad, por una parte, y la creatividad humana, por otra, entre la apertura y la capacidad de sorpresa presentes en lo real y la capacidad de sorpresa del ser humano" (61). E. Bloch, el filósofo de la esperanza, subraya que en la realidad "ocurren cosas verdaderamente nuevas... Cosas que verosímilmente aún no le habían ocurrido a ninguna realidad... Hay condicionamientos que nosotros no conocemos aún, o que ni siquiera existen por ahora... Vivimos rodeados de la posibilidad, no solo de la presencia" (62).

'Vivimos rodeados de la posibilidad, no solo de la presencia', afirma Bloch. En este punto $X$. Zubiri podría estar plenamente de acuerdo con el pensamiento de Bloch. ¿Qué es la posibilidad?, según el filósofo vasco. Zubiri ve la posibilidad como algo radical. "No puede haber diferencia ni constitución de fines ni de medios sino en el seno de una posibilidad. La posibilidad es la estructura primaria y radical dentro de la cual puede haber finalidad y mediación" (63). Es la estructura básica que permite igualmente comprender la historia. Para introducir su respuesta Zubiri dialoga críticamente con Aristóteles. Recuerda que Aristóteles habló de la posibilidad, de la dynamis en dos sentidos distintos. En primer lugar, la dynamis como potencia activa, como "capacidad que tiene alguien de actuar sobre otro en tanto que otro". En segundo lugar, se refiere a "la índole de una realidad que está solo potencialmente contenida en otra realidad". Por ejemplo, la encina que no es actual mientras no haya más que bellotas. Cuando se señala que algo está o estaba en potencia, dynamei on, contenido potencialmente en otra realidad. Para Zubiri ambos sentidos de la potencia no son suficientes para aprehender conceptualmente lo que es la posibilidad y explica su propia visión destacando las siguientes características de la posibilidad: por un lado, la posibilidad implica siempre un momento plural, no hay nunca una posibilidad aislada; por otro lado, posibilidades es un fenómeno propiamente humano; es en orden a la realidad que se constituyen y el hombre está vertido a la realidad.

Zubiri observa que en los dos casos planteados por Aristóteles se contrapone la potencia al acto. El problema está en que el concepto de acto es ambiguo. En una primera aproximación, el acto sería la actuación de una potencia. Pero hay otro sentido de la palabra acto en el cual se alude al acto en el sentido de acción. "No es lo mismo el acto que la acción. La acción es un sistema funcional, un sistema funcional de actos, un sistema rigurosamente hablando. Es lo que hace que el concepto aristotélico de dynamis resulte insuficiente para aprehender las posibilidades. Porque aquello de que las posibilidades son posibilidades, no es actos; aquello de que son posibilidades son acciones" (64). Zubiri denomina 'hecho' a la actualidad o al acto de una potencia y 'evento' o 'suceso' a la actualidad o al acto de una posibilidad. "La vida humana no está compuesta de hechos sino de sucesos. Ciertamente, hay muchos hechos en la vida humana, pero no constituyen un momento de la vida si no son reabsorbidos justamente en forma de sucesos" (65).

(61) TAMAYO-ACOSTA, o. c., p. 20.

(62) E. BLOCH, Man as possibility: Cross Currents 18 (1968) p. 279, 281.

(63) X. ZUBIRI, Estructura dinámica de la realidad, 2a ed., Ed. Alianza, Madrid, 1995, p. 229.

(64) Ibíd., p. 232.

(65) Ibíd., p. 236. 
El ser humano tiene que apropiarse de unas posibilidades y rechazar otras, tiene que elegir entre unas posibilidades determinadas. En eso precisamente reside su dinamismo. "La causalidad en orden a la posibilidad, por parte del hombre, es apropiación” (66). El dinamismo de la personalización es justamente el apoderamiento de posibilidades. Este apoderamiento de las posibilidades envuelve un momento dinámico anterior que es la proyección, el proyecto. En palabras de Zubiri, "toda posibilidad es un proyecto incoado" (67). Ahora bien, continúa Zubiri, "en el proyecto está justamente algo que por lo pronto no es real, es algo irreal. Decir que el hombre es una forma de realidad que no puede ser justamente el mismo, que no puede ser suyo como persona sino personalizándose, equivale por consiguiente a decir que el hombre, en muchas dimensiones de su vida, no puede ser realmente lo que es sino pasando por el rodeo de la irrealidad" (68). En efecto, “...mientras las dynamis, potencias, 'brotan' de la realidad, las posibilidades tiene que 'determinarlas' el hombre... (El hombre) produce la posibilidad de la realidad antes que producir la realidad. Justamente, es en lo que se parece a la Creación... la vida humana es cuasi creación. Es una cuasi creación porque, antes que en producir realidad, consiste precisamente en producir la posibilidad que se va a actualizar en las acciones de su realidad" (69).

Sobre esta base Zubiri definirá lo que entiende por historia: La historia no es desarrollo ni evolución, ni fluencia, es algo distinto: "es pura y simplemente transcurso. Es un transcurso en el que transcurren precisamente las posibilidades, unas ampliadas, otras reducidas; unas anuladas, otras cambiadas... Pero la historia es justamente un sistema de actualización de posibilidades, no de actualización de potencias" (70). A diferencia de los seres humanos que se ven en la necesidad de personalizarse para seguir siendo los mismos, la historia carece de una mismidad en un sentido radical. Por ello, afirma Zubiri, "la historia es una estructura abierta", la historia está abierta al mundo, no tiene ningún empeño especial en mantener las estructuras de las cuales vive en el presente, podrá en un futuro cambiarlas siempre a partir de las posibilidades que ha recibido. "La historia está abierta a un tipo de mundo distinto" (71).

El mundo no se caracteriza por ser estático y cerrado, sino por su constante disposición hacia algo que todavía no ha acontecido. En términos de Bloch, ese algo es un mundo más adecuado al ser humano, un mundo sin sufrimiento, sin violencia ni injusticia, un mundo mejor que el presente. Para Bloch, la esperanza es el afecto más importante. Es también la emoción más humana y solo humana, "El modo humano del instinto de conservación". A continuación de esas primeras intuiciones, Bloch estudia la esperanza como hábito operativo; es decir, además de ser un constitutivo biológico de la existencia humana, la esperanza constituye un rasgo específi-

(66) Ibíd., 235.

(67) Ibíd., p. 238.

(68) Ibíd, p. 238.

(69) Ibíd., p. 239, cf., X. ZUBIRI, Naturaleza, Historia, Dios, 9a ed., Ed. Alianza, Madrid, 1987, p. 330.

(70) ZUBIRI, Estructura dinámica de la realidad..., p. 269.

(71) Ibíd., p. 270. 
camente humano de proyección. Es precisamente, la esperanza activa como impulso de autoexpansión hacia adelante. "Se trata -dice Bloch-de aprender de la esperanza... La esperanza, situada sobre el miedo, no es pasiva como este, ni, menos aún, está encerrada en un anonadamiento. El afecto de la esperanza sale de sí, da amplitud a los hombres en lugar de angostarlos... La vida en todos los hombres se halla cruzada por sueños soñados despierto (de una vida mejor)... No hay hombre que viva sin soñar despierto... Pensar significa traspasar... Solo con el abandono del concepto concluso-estático del ser aparece en el horizonte la verdadera dimensión de la esperanza. El mundo está más bien en una disposición hacia algo, en una tendencia hacia algo, en una latencia de algo, y este algo que se persigue se llama la plenitud del que lo persigue: un mundo que nos sea más adecuado, sin sufrimientos indignos, sin temor, sin alienación de sí, sin la nada” (72).

La misma dimensión histórica nos lleva a descubrir la realidad humana como finitud, contingencia y limitación, pero, al mismo tiempo experimentamos un incontenible deseo de ser más hombres. En efecto, el hombre es un ser inacabado. Siempre somos más de lo que hacemos, de lo que pensamos y deseamos. Nuestra existencia de hecho discurre entre la finitud y la infinitud que asoma en todos nuestros anhelos y aspiraciones. Por lo mismo experimentamos nuestra vida como una interminable búsqueda de satisfacer cabalmente nuestros deseos. Búsqueda en la cual, muchas veces, descubrimos el dolor de la insatisfacción plena y absoluta. El hombre-mujer va en busca de su verdadero ser, de la patria "donde nadie ha estado todavía" (Bloch).

La esperanza dirige, pues, la actividad humana hacia una meta futura. El ser humano entero, deseos, cuerpo y razón, se orientan hacia el futuro. La razón forma parte de la esencia de la espera y de la esperanza: señala objetivos, guía, orienta la acción humana, relaciona la imaginación con los deseos y el saber. La razón convierte a la esperanza en 'docta spes'. Como bien señala Bloch: "La razón no puede florecer sin esperanza ni la esperanza puede hablar sin razón” (73).

La esperanza "va siempre más allá de sus esperanzas; su futuro trasciende inevitablemente todas sus concretas realizaciones" (74). En otro lugar, el mismo Alfaro destaca que "la ley fundamental del actuar del hombre es que toda meta alcanzada viene a ser punto de partida para nuevos logros: es pues una apertura siempre abierta que en el acto mismo de crear lo nuevo lo trasciende hacia lo siempre nuevo sin poder nunca ser el nuevo definitivo, último: todo lo alcanzado lleva el carácter insuperable de lo penúltimo" (75). La experiencia de estar inacabado nos lleva a la esperanza. La esperanza vive de la experiencia del rebasamiento. Nostalgia, añoranza, anhelo, promesa y utopía... nos hablan de la esperanza que vive más allá de los límites. El gesto esperanzado recorre todos los niveles humanos. El sufrimiento y el dolor contienen gérmenes de esperanza, porque al interior de su experiencia sentimos la nostalgia que ansía la alegría y el gozo de la vida. La experiencia de la felicidad misma lleva en su seno la nostalgia de una felicidad sin

(72) E. BLOCH, El principio esperanza I, Ed. Trotta, Madrid, 2004, pp. 25, 26, 42.

(73) E. BLOCH, El principio esperanza III, Ed. Aguilar, Madrid, 1977, pp. 491-492. El subr. es mío.

(74) J. ALFARO, Las esperanzas intramundanas y la esperanza cristiana: Concilium 59 (1970) 353.

(75) J. ALFARO, Revelación Cristiana, Fe y Teología, Ed. Sígueme, Salamanca, 1994, p. 23. 
límites, de una plenitud que desborde los anhelos de paz que surgen en el ser humano y que no tenga fin.

Reflexionando lo anterior notamos que, en última instancia, la experiencia de trascender permanentemente las propias realizaciones nos remite al Absoluto. Y en ese sentido, la trascendencia se constituye en fundamento de la experiencia religiosa. A los rasgos característicos de la persona: relación consigo misma, relación con el mundo, relación con los otros y la sociedad, hay que añadir su apertura a la Trascendencia absoluta. La cual, si se asume con responsabilidad desde una experiencia creyente es una relación a lo totalmente Otro, al Absoluto, a Dios. La persona, en su más alto grado de realización, surgirá entonces en su apertura -junto a todos los hombres- hacia el referente común y esencial: Dios mismo. Por ello, la historia vive de una esperanza "que la empuja permanentemente más allá de todo lo devenido intrahistórico hacia lo nuevo que vendrá" (76). En suma, la historia permanece abierta hacia el futuro de Dios.

\section{HISTORIA Y PROGRESO}

En la actual búsqueda de una conciencia más auténtica del tiempo, retorna el interés por el pensamiento de W. Benjamin, quien ha establecido una crítica original a las filosofías de la historia centradas en la convicción del progreso. W. Benjamin expresa su visión de la historia en la estremecedora imagen del "ángel de la historia" que desarrolla en la Tesis IX (tesis sobre el concepto de historia) (77): "Hay un cuadro de Klee que se titula Angelus Novus. Se ve en él un ángel al parecer en el momento de alejarse de algo sobre lo cual clava la mirada. Tiene los ojos desencajados, la boca abierta y las alas desplegadas. Es la figura del ángel de la historia. Su cara está vuelta hacia el pasado. En lo que para nosotros aparece como una cadena de acontecimientos, él ve una catástrofe única, que acumula sin cesar ruina sobre ruina y se las arroja a sus pies. El ángel quisiera detenerse, despertar a los muertos y recomponer lo despedazado. Pero una tempestad desciende del Paraíso que impulsa sus alas y el ángel no puede plegarlas. Esa tempestad lo arrastra irresistiblemente hacia el futuro, al cual vuelve las espaldas, mientras el cúmulo de ruinas sube ante él hacia el cielo. Tal tempestad es lo que llamamos progreso".

¿Cómo interpretar esta imagen? Lo que a nosotros nos parece una lógica de acontecimientos es para el ángel pura catástrofe. Se trata de dos filosofías diametralmente contrapuestas: la que simboliza el ángel y la que simboliza la tempestad. La tempestad remite a una concepción de la historia como dinámica de poder y de dominio. Es el progreso. Por su parte, el ángel de la historia no puede consolarse con la filosofía de la historia que nosotros vemos porque entiende que tantos sacrificios pasados y presentes no pueden interpretarse como el precio del futuro. Benjamin ve el futuro en el pasado: "frente a la imagen kantiana de un profeta-político que determina racionalmente el curso de la historia está esta otra imagen del hombre

(76) J. ALFARO, Revelación Cristiana..., p. 49.

(77) W. BENJAMIN, Obras Escolhidas I, Brasiliense, Sao Paulo, 1985, pp. 222-232. 
que relaciona la liberación con la atención puesta en los gritos que vienen de atrás, reclamando que se les haga justicia" (78). Mientras "el progreso mira al pasado con horror, para huir de él; el ángel de la historia se horroriza del costo de la historia y quiere hacerse cargo de él. Esa es la diferencia" (79). El futuro queda desprovisto de su capacidad innovadora y el pasado es solo la prehistoria, la acumulación de condiciones para que por fin estalle la verdadera historia. El sujeto se reduce a un reproductor de lo dado y se muestra incapaz de trascender su propio presente. Se afirma una necesaria continuidad en la historia. Por ello, algunos intérpretes destacan que Benjamin ha percibido la necesidad de desmontar el supuesto fundamental sobre el que se apoya la ideología del progreso. "Este supuesto es ontológico. En efecto, el predominio del presente, bajo el cual se lleva a cabo la reducción de la historicidad de lo histórico, concierne a una concepción del ser que, por decir así, mantiene bajo control en él la diferencia tempórea. Para esta concepción el 'es' designa la coincidencia -falsamente feliz- de ser y tiempo, el instante en que el 'es' coincide puntualmente consigo mismo, signando su propia identidad. El formato teórico de una tal coincidencia es una ontología del presente" (80). Contra sus propias intenciones el progresismo histórico no solo acaba construyendo un presente de identidad sino que pierde toda capacidad de elaborar una crítica del presente.

Camino decisivo para superar esta tendencia a la ontologización del presente es el recuerdo (81). Solo la memoria, o lo que Reyes Mate denomina razón anamné-

(78) REYES MATE, La razón de los vencidos, Anthropos, Barcelona, 1991, p. 207.

(79) Ibíd., 207. La reflexión de Benjamin implica una determinada concepción del tiempo. Para él, el auténtico tiempo histórico no es un tiempo vacío y homogéneo, un flujo continuo en el que todo acontecer discurre de modo indiferente. Es precisamente esta visión de la historia propia del historicismo moderno la que Benjamin quiere superar. Para ello propone un tiempo cualitativo, pleno, "lleno de ahoras". La historia "como un continuo vacío y duradero de sucesos destruye el valor único y permanente de cada acontecimiento. Es el "enemigo" siempre victorioso ante el cual no están seguros los vivos ni los muertos, porque quedan todos olvidados y en este sentido aniquilados. Por eso es preciso romper el tiempo como continuun para poder liberar y fijar determinados acontecimientos (pasados) como tiempo abolutamente significativo, 'pleno', para el presente y el futuro: lo pasado debe guardar lo permanentemente válido y lo totalmente nuevo" (M. KEHL, Escatología, Sígueme, Salamanca, 1992, pp. 336-337). El concepto de 'ahora', propuesto por Benjamin "lleva incrustradas astillas del tiempo mesiánico o de la consumación del tiempo". Con razón, J. Habermas puede comentar que hay aquí una propuesta que se vuelve "contra la idea de un tiempo homogéneo y vacío que queda lleno por la 'obtusa fe en el progreso', que caracteriza al evolucionismo y a la filosofía de la historia" (J. HABERMAS, Perfiles filosófico-políticos, $2^{\text {a }}$ ed., Taurus, Madrid, 1986, p. 22).

(80) P. OYARZÚN, Introducción, en W. BENJAMIN, La dialéctica en suspenso. Fragmentos sobre la historia, Lom-Arcis, Santiago de Chile, 1996, p. 33. Oyarzún recoge la noción 'ontología del presente' elaborada por REYES MATE en "La historia de los vencidos. Un ensayo de filosofía de la historia contra las ontologías del presente", en J. GÓMEZ CAFFARENA Y J. M. MARDONES (coords.), Cuestiones epistemológicas. Materiales para una filosofía de la religión. I. CSIC, Anthropos, Barcelona, 1992, pp. 183-207. Del mismo REYES MATE ver: La razón de los vencidos... (cit. en la nota 78).

(81) Este recurso a la memoria se acerca al planteo de Berdiaev cuando la propone como superación del tiempo desgarrado sobre el que se construye el progreso, "en el que el pasado parece algo meramente transcurrido y el futuro se nos presenta como algo aún no nacido, de tal manera que nos encontramos encerrados en el instante de un dudoso presente, hay un principio... sin el cual no sería posible la unidad de la historia, su integridad, el nexo interior al tiempo... La memoria es este principio" (El sentido de la historia..., p. 72). "A través de la memoria, restauramos lo que se ha alejado de nosotros, lo que ha muerto y casi se ha ahogado en el oscuro abismo del pasado" (ibíd., p. 73). 
tica puede salvar del olvido del pasado, de aquel pasado trunco, que no se pudo realizar en su presente. Privilegiar el pasado no implica un vaciamiento del futuro sino que, por el contrario, permite mantener realmente abierto el porvenir. En este sentido, "el pasado se convierte en la piedra de toque de toda concepción de la historia que quiera escapar al peligro de una ontologización del presente. Se podría pensar que nada como el futuro para deshacer la prepotencia del presente. Pero el futuro solo es tal -la posibilidad de la novedad radical- cuando lo porvenir sea algo distinto a la prolongación del presente. El futuro supone ya un presente quebrado y la quiebra del presente es un asunto entre este y el pasado" (82).

Benjamin da que pensar sobre el asunto pero deja abiertos nuevos problemas. Por un lado parece revalorar con fuerza un aspecto de la tradición que se remonta a San Agustín y a H. Bergson (83) al sugerir que la esencia del tiempo es el hecho de la retención. En esta concepción el tiempo no es solo medida, número, como afirmaba Aristóteles, sino paso. El sujeto "retiene los pasos de ese paso". En una palabra, lo esencial del tiempo es la memoria como retinente de un pasado. No queda claro cómo articular esta dimensión con el hecho de que el sujeto no solo retiene sino que proyecta, va hacia algo o alguien. Por otro lado, en Benjamin no se resuelve el problema de la mediación para enfrentar creativamente el devenir histórico (84).

\section{HISTORIA, TIEMPO Y TEOLOGÍA}

La fe judeocristiana valora todos los tiempos porque cree en un Dios de vivos y muertos, en el Dios de la promesa (85), sentido de todo acontecer, por tanto, Dios de la historia. En la raíz de este enfoque parece estar la asimilación de la peculiar experiencia hebrea del tiempo. Preguntándose ¿cómo ha existido el hombre hebreo en el mundo?, X. Zubiri, observa que "el hebreo no siente el transcurso de las cosas y su efímera existencia como un 'movimiento' al modo griego, sino como una historia que algún día el futuro sancionará, esto es, rectificará o ratificará. (...) La verdad es cuestión de tiempo. No es un tiempo como el del griego, pura duración cósmica, sino el tiempo de cada cosa, de cada acontecimiento. El tiempo de la historia no es el tiempo del simple movimiento, sino el tiempo del destino. Este tiempo oculta el secreto que promete todo cuanto hay. Lo que las cosas son, su destino, será transparente por esto cuando llegue la 'consumación de los siglos'. En su radical soledad, el hebreo espera la consumación de los tiempos. En aquella soledad se ha formado el horizonte del destino, desde el cual aparece el universo como historia. Y lo que las cosas son está allende su historia. (...) El destino es siempre, para el hebreo, una promesa, 'una palabra', y, por tanto, la cuestión del ser es cuestión de fidelidad. (...) Mientras, para el griego, el movimiento indica la

(82) REYES MATE, o. c., La razón de los vencidos..., pp. 202-203.

(83) H. BERGSON, Ensayo sobre los datos inmediatos de la conciencia, Ed. Sígueme, Salamanca, 1999 y del mismo H. BERGSON, Memoria y vida (textos escogidos por Gilles Deleuze), Ed. Alianza, Madrid, 2004.

(84) Cf. KEHL, o. c., p. 33.

(85) Cf. J. MOLTMANN, Teología de la esperanza, Ed. Sígueme, Salamanca, 1977; J. RATZINGER, Introducción al cristianismo, Ed. Sígueme, $12^{\mathrm{a}}$ ed., Salamanca, 2005, pp. 104-105. 
physis, como principio o arché del universo, para el hebreo, el tiempo indica más bien, si se me permite, un arconte, un señor, 'adonai', que dio una palabra. Este señor es Yahweh, Dios. El destino, en la visión israelita del mundo, es todo, menos fatalidad; es confianza en Yahweh, fe en su palabra. Ante el mundo, el griego dice 'es', y el hebreo dice: 'así sea' (amén). En lugar de la visión del todo, que el griego llamó teoría, tenemos aquí otra visión del todo, esencialmente distinta: la escatología" (86).

En una línea semejante, M. Eliade, ha destacado que en la experiencia religiosa hebrea "por vez primera se ve afirmarse y progresar la idea de que los acontecimientos históricos tienen un valor en sí mismos, en la medida en que son determinados por la voluntad de Dios. Ese Dios del pueblo judío ya no es una divinidad oriental creadora de hazañas arquetípicas sino una personalidad que interviene sin cesar en la historia, que revela su voluntad a través de los acontecimientos (...) Por eso es posible afirmar que los hebreos fueron los primeros en descubrir la significación de la historia como epifanía de Dios, y esta concepción, como era de esperar, fue seguida y ampliada por el cristianismo" (87). Como lo han subrayado tanto G. von Rad (88) como S. Mowinckel en la cultura judía bíblica el tiempo no es cuantitativo sino cualitativo. Para este último el tiempo bíblico no es "una noción formal y vacía, un concepto o categoría en el sentido kantiano, sino que es inseparable de la totalidad de su contenido. 'El tiempo' es todo lo que existe y sucede en el tiempo" (89). En suma, estamos frente a una diferenciación cualitativa del tiempo. No se puede pensar el tiempo sin relación al acontecer, el tiempo es la cualidad de una experiencia humana. Y si el acontecer se describe como un despliegue proyectivo de pasado, presente y futuro (90), Dios es sentido de todos estos modos del tiempo. En suma, surge así una peculiar comprensión de la historia marcada por la experiencia creyente vetero y neotestamentaria fundada en Dios Creador y Consumador del mundo y de la historia (91).

En la actualidad, se impone la necesidad de un rescate del tiempo.

Algo pasa con el tiempo personal y sobre todo con la experiencia del tiempo común. Es más, se advierte una situación desconcertante, descrita acertadamente por el filósofo H. Giannini como "un nuevo y extraño modo de soledad: la de estar atadas a las otras por múltiples lazos, todos precarios, convencionales, desechables. La desolación que significa la tangencia -la sola tangencia-... de múltiples discursos que se tocan en algún punto, que están de soslayo, sin llegar a confluir hacia un tiempo verdaderamente solidario, común. En todo caso, desolación por una suerte de falsa presencia de los otros o por una presencia deficitaria. Un puro estar juntos"

(86) X. ZUBIRI, Sobre el problema de la filosofía y otros escritos (1932-1944), Ed. Alianza, Madrid, 2002, pp. 54-55.

(87) M. ELIADE, El mito del eterno retorno, Ed. Alianza, Madrid, 1995, p. 98.

(88) G. VON RAD, Teología del antiguo testamento II, 60 ed., Sígueme, Salamanca, 1990, p. $132 \mathrm{~s}$.

(89) S. MOWINCKEL, El que ha de venir. Mesianismo y Mesías, Ed. Fax, Madrid, 1975, pp. 116-117, 199.

(90) X. ZUBIRI, Sobre el Hombre, Alianza, Madrid, 1986, Pp. 611-618.

(91) Al respecto me permito remitir a F. PARRA, "La comprensión cristiana de la historia", en S. YÁÑEZ-D. GARCÍA, eds., El porvenir de los católicos latinoamericanos, Centro Teológico Manuel Larraín, PUC-UAH, Santiago, 2006, pp. 15-30. 
(92). Palabras que me recuerdan aquellas reflexiones de E. Levinas manifestadas en tiempos donde esperar era tan necesario como difícil: "La soledad no es trágica porque es privación del otro, sino porque está encerrada en la cautividad de su identidad... La soledad es una ausencia de tiempo" (93). Además de cierta desolación se advierte la experiencia de una rutina entendida como "regreso a lo consabido, a lo mismo". Vista desde su cualidad -que es lo que interesa evocar aquí- "la rutina consiste en una suerte de absorción de la trascendencia del futuro, absorción en la normalidad de un presente continuo e idéntico a sí" (94); un tiempo, en suma, quieto e intrascendente.

En este contexto, se trata de asumir positivamente el tiempo y de escudriñar en las diferencias internas del tiempo mismo. Es decir, se trata también de un volver al tiempo íntegro, de rescatar, en términos de X. Zubiri (95), la "realidad tempórea" del sujeto. ¿De qué modo puede contribuir la teología a enfrentar este desafío? Por de pronto, rescatando ella misma su propia temporalidad, y por lo mismo, haciéndose cargo de la fe en un Dios, Señor del tiempo y de la historia, que se ha revelado en el tiempo y lo conduce hacia su plenitud. La experiencia cristiana cree firmemente que la eternidad ha visitado y visita al tiempo. La Encarnación, la venida del reino de Dios, el don del Espíritu muestran que este tiempo nuestro no es un tiempo devaluado ni marginal. Por el contrario, el tiempo queda atravesado por la eternidad y el tiempo cronos se convierte en kairós. Por ello, la fe cristiana invita al ser humano a vivir su vocación en medio del tiempo en la esperanza de la parusía y la resurrección. Creer en el Crucificado-Resucitado-que-ha-de-venir funda y nutre toda esperanza. Por este motivo, se hace igualmente necesaria una reflexión teológica sobre la historia que asuma positivamente la fe en la parusía como límite plenificador del tiempo y que sea capaz de enfrentar creativamente el desafío de una relación armónica entre pasado, presente y futuro, esto es, ayudar a pensar de nuevo la tensión entre continuidad y novedad en el tiempo sin resignarse a una ontologización del presente. Es preciso subrayar que la llegada futura del reino o su plenitud, es decir, la parusía, implica un límite al tiempo, y que por ello, constituye su condición de posibilidad (96). Negar la parusía y junto con ella la expectativa cercana que conlleva, no solo deja en la penumbra la tensión escatológica inherente al pensa-

(92) H. GIANNINI, Del bien que se espera y del bien que se debe, Dolmen, Santiago de Chile, 1997, p. 35 .

(93) E. LEVINAS, Le temps et l'autre, 1948, p. 38. Ed. en castellano: El tiempo y el otro, Paidós, Barcelona, 1993, p. 95.

(94) H. GIANNINI, La "Réflexión” quotidienne. Vers une archéologie de l'expérience, Alinea, París, 1992, pp. 32-33. Y añade "Caricatura de la eternidad... Una existencia rutinaria es tal en cuanto no se abisma en los abismos del tiempo, en cuanto nivela todas sus dimensiones y simplemente 'es' lo que viene de ser (donde pasar y pasado se confunden), y espera ser lo que proyecta en un futuro sin distancia;... en un tiempo continuo, pegado a la actualidad y movido por la norma. Tiempo quieto, intrascendente ... Tampoco puede decirse que no espera nada del futuro. Espera, pero sin salir al encuentro de lo esperado. Y es así como la rutina acaba por hacer inofensivos sus propios proyectos, por miedo a salirse del trayecto... En tal visión, el futuro no aparece ni como favorable ni como amenazante: parásito de un desértico hoy, llega continua, mansamente, como norma y normalidad. Y así también, el pasado: como lo que soy 'pasando la vida', irremediablemente".

(95) X. ZUBIRI, Sobre el Hombre..., p. 618

(96) J. B. METZ, La fe en la historia y la sociedad, Ed. Cristiandad, Madrid, 1979, p. 183. 
miento de Jesucristo, asumida por la comunidad cristiana primitiva, sino que de paso priva a la esperanza cristiana, de ayer y de hoy, de sus dimensiones colectivacomunitaria, mundana y temporal. La historia posee sentido en la misma medida en que se orienta hacia un fin consumador y plenificador de la totalidad del acontecer histórico.

De lo que se trata, en suma, es que el futuro no sea aparente ni mera repetición del presente sino realmente abierto, proyectivo y cualitativo; asimismo, se trata de respetar todo tiempo, asumir integralmente el pasado, el presente y esperar el futuro. Y esto es asunto no solo de utopía sino también de memoria, y, ciertamente, de confianza paciente en el Dios Padre de Jesucristo.

\title{
RESUMEN
}

El artículo reflexiona sobre diversas dimensiones y tensiones de la temporalidad: Se muestra que el tiempo de la vida humana es, a la vez, duración, proyección y destinación, y se profundiza en los momentos de la línea proyectiva propia del acontecer, a saber, pasadopresente-futuro. A seguir se define la historicidad como aquella experiencia fundamental por la que el hombre, sujeto libre, se encuentra entre un pasado ya dado y un futuro porvenir-por crear, y se indagan sus tensiones. Por el hecho de ser como es, el hombre tiene que esperar y ve su existencia como un proyecto inconcluso, abierto a la novedad. La existencia humana vive rodeada de la posibilidad, no solo de la presencia. Por lo mismo, el artículo esboza una crítica a las filosofías del progreso que, al no superar una ontología del presente, pierden su fuerza innovadora y dañan sus vínculos con el pasado y el futuro. Se trata de rescatar el pasado sin renunciar al futuro. Solo la razón anamnética, la memoria, puede salvar del olvido del pasado. Finalmente, se plantea que la fe judeocristiana valora todos los tiempos porque precisamente cree y espera en Dios Creador y Consumador, Dios de vivos y muertos, en una palabra, Señor de la historia y de todos los tiempos.

Palabras clave: Tiempo, historicidad, posibilidad, memoria.

\begin{abstract}
This article reflects upon the diverse dimensions and tensions of temporality: the time of human life is shown to be, at the same time, duration, projection and destination, and deepens in the moments of the projective line proper to events-that is, past-present-future. Then historicity is defined as that fundamental experience through which the human person, as a free subject, is found between a given past and a future yet to be created. The tensions involved are examined. Just by being as one is, the human person has to wait, and sees his or her existence as an inconclusive project, open to novelty. Human existence lives surrounded by possibility, and not only presence. For this reason, the article seeks to outline a criticism of the philosophies of progress that, upon failing to overcome an ontology of the present, lose their innovative force and damage their links with the past and the future. The idea is to rescue the past without disregarding the future. Only amamnetic reason, or memory, can save us from the forgetfulness of the past. Finally, the article proposes that Judeo-Christian faith values all time precisely because it believes in and awaits God, Creator and Consummate, the God of the living and the dead-in a word, the Lord of history and of all time.
\end{abstract}

Key words: Time, historicity, possibility, memory. 
